\title{
Correction to: Predictors of improvement in resting heart rate after exercise training in patients with chronic obstructive pulmonary disease
}

\author{
Illknur Naz ${ }^{1}$ Hülya Şahin ${ }^{2}$ Büşra Aktaş̧ ${ }^{3}$
}

Published online: 11 October 2021

(c) The Author(s), under exclusive licence to Royal Academy of Medicine in Ireland 2021

Correction to: Irish Journal of Medical Science (2021)

https://doi.org/10.1007/s11845-021-02771-4

The above article was published online with error. In Table 3, beta values in parentheses are written incorrectly.

The original article has been corrected.

Publisher's Note Springer Nature remains neutral with regard to jurisdictional claims in published maps and institutional affiliations.

The original article can be found online at https://doi.org/10.1007/ s11845-021-02771-4.

\footnotetext{
İlknur Naz

ilknurnaz4@gmail.com

1 Department of Physiotherapy and Rehabilitation, Faculty of Health Sciences, Izmir Kâtip Celebi University, İzmir, Turkey

2 Dr. Suat Seren Chest Diseases, Chest Diseases Clinic, Thoracic Surgery Training and Research Hospital, University of Health Sciences, Izmir, Turkey

3 Institute of Health Sciences, Izmir Kâtip Celebi University, Izmir, Turkey
} 